\title{
Analisis Nilai Ketidakpastian dan Faktor Kalibrasi pada Alat Ukur Radiasi di Balai Pengamanan Fasilitas Kesehatan Surabaya
}

\author{
Kardianto, ${ }^{1}$ Kurnia Hastu Kristanti, ${ }^{2}$ Kandi Ayu Tiswati, ${ }^{1}$ dan Yanurita Dwihapsari*2 \\ ${ }^{1}$ Instalasi Kalibrasi Alat Ukur Radiasi, Balai Pengaman Fasilitas Kesehatan (BPFK) \\ Jl. Karang Menjangan No.22, Surabaya 60286 \\ ${ }^{2}$ Departemen Fisika, Fakultas Sains, Institut Teknologi Sepuluh Nopember Surabaya (ITS) \\ Kampus ITS Keputih Sukolilo, Surabaya 60111
}

Intisari

\begin{abstract}
Kalibrasi alat ukur radiasi (AUR) wajib dilaksanakan oleh rumahsakit dan fasilitas kesehatan sesuai Peraturan Menteri Kesehatan Nomor 54 tahun 2015 dengan menyertakan ketidakpastian pengukuran. Studi kalibrasi AUR pada fasilitas-fasilitas kesehatan yang ada di Jawa Timur telah dilaksanakan di Balai Pengaman Fasilitas Kesehatan Surabaya. Penentuan nilai ketidakpastian dan faktor kalibrasi dilaksanakan terhadap 20 dosimeter saku analog, 20 dosimeter saku digital dan 10 surveimeter gamma dengan sumber acuan Cs-137. Dari 40 dosimeter saku serta10 surveimeter gamma yang diuji, hanya 1 dosimeter saku analog tidak layak digunakan karena memilikinilai faktor kalibrasi di luar standar yang telah ditetapkan.
\end{abstract}

\begin{abstract}
Radiation measurement calibration for ionizing radiation instrument is a compulsory procedure in hospitals and health facilities according to Minister of Health Regulation No. 54/2015. This study observed radiation measurement calibration in health facilities across East Java and was conducted at Surabaya Health Facilities Security Center (Balai Pengamanan Fasilitas Kesehatan Surabaya). The uncertainty and calibration factor were measured and calculated on 20 analog pocket dosimeters, 20 digital pocket dosimeters and 10 gamma surveymeters with reference sources of Cs-137. From 40 pocket dosimeters and 10 gamma surveymeters, only 1 analog pocket dosimeter was not feasible to use because its calibration factor was outside the allowed standard value.

Keywords: calibration; uncertainty; pendosimeter; surveymeter.

*Corresponding author: yanuritadh@physics.its.ac.id
\end{abstract}

http://dx.doi.org/10.12962/j24604682.v15i2.4698

2460-4682 (C)Departemen Fisika, FSains-ITS

\section{PENDAHULUAN}

Alat ukur radiasi pada umumnya dibedakan menjadi tiga yaitu kelompok dosimeter personal, surveimeter dan monitor kontaminasi. Dosimeter personal biasanya digunakan untuk mengukur dosis radiasi yang diterima pekerja radiasi. Dosimeter personal yang banyak digunakan pada fasilitas kesehatan terdiri dari dosimeter saku (pen dosimeter), film badge, dan dosimeter luminesen (Thermoluminesence Dosimeter, TLD). Surveimeter digunakan untuk mengukur besarnya radisi di lingkungan atau suatu lokasi secara langsung sedang monitor kontaminasi digunakan untuk mengukur tingkat kontaminasi pada pekerja, alat maupun lingkungan [1].

Peraturan Kepala Badan Pengawas Tenaga Nuklir (BAPETEN) Nomor 1 tahun 2006 mensyaratkan kalibrasi alat ukur radiasi pada fasilitas-fasilitas kesehatan dilakukan setiap tahun oleh institusi pemerintah yang telah ditunjuk BAPETEN atau sudah tersertifikasi [2]. Hal ini merupakan salah satu syarat operasional rumah sakit maupun fasilitas kesehatan sesuai Peraturan Menteri Kesehatan Nomor 54 tahun 2015 [3]. Balai Pengamanan Fasilitas Kesehatan (BPFK) Surabaya merupakan salah satu instansi pemerintah yang diberikan wewenang untuk mengkalibrasi alat ukur radiasi pada fasilitas kesehatan seperti puskesmas dan rumah sakit di wilayah kerjanya melalui Instalasi Kalibrasi Alat Ukur Radiasi (KAUR) dan dalam menjalankan tugasnya sesuai standar baku mutu yang telah disaratkan oleh BAPETEN. Instalasi KAUR BPFK Surabaya juga telah terakreditasi oleh Komite Akreditasi Nasional (KAN) No. LK-132-IDN tanggal 10 Desember 2014 sebagai laboratorium kalibrasi yang telah menerapkan SNI ISO/IEC 17025:2008 (ISO/IEC 17025:2005) secara konsisten.

Menurut Biro Internasional untuk Ukuran dan Timbangan (BIPM), kalibrasi didefinisikan sebagai "serangkaian kegiatan 
yang membentuk hubungan antara nilai yang ditunjukkan oleh instrumen ukur atau sistem pengukuran atau nilai yang diwakili oleh bahan ukur, dengan nilai-nilai yang sudah diketahui yang berkaitan dengan besaran yang diukur dalam kondisi tertentu" [4]. Kalibrasi alat ukur radiasi di instalasi KAUR BPFK Surabaya dilakukan untuk menguji ketepatan nilai yang ditampilkan alat terhadap nilai sebenarnya dengan cara menyinari alat tersebut dengan sumber radiasi standar. Perbedaan nilai yang ditampilkan pada alat dengan nilai sebenarnya dinyatakan dengan faktor kalibrasi (FK). Faktor kalibrasi (FK) pada AUR didapatkan dari perbedaan antara laju dosis/dosis pada titik pengukuran dan laju dosis/dosis yang terbaca pada AUR sebagai berikut [5]

$$
F K=\frac{D_{S}}{D_{U}}
$$

dengan $\mathrm{D}_{S}$ adalah nilai laju dosis/dosis acuan yang telah ditetapkan oleh laboratorium kalibrasi dan $\mathrm{D}_{U}$ adalah nilai laju dosis/dosis yang terbaca oleh alat ukur yang akan dikalibrasi. Idealnya faktor kalibrasi ini bernilai satu namun pada kenyataannya tidak banyak alat ukur yang mempunyai faktor kalibrasi sama dengan satu. Nilai faktor kalibrasi yang masih dapat diterima berkisar $1 \pm 20 \%$ dengan nilai antara 0,8 dan 1,2 .

Sesuai standar yang telah ditetapkan oleh Badan Standardisasi Nasional (BSN) dan KAN yaitu Guide on The Evaluation and Expression of Uncertainty in Measurement atau ISO GUM, hasil pengukuran kalibrasi yang dilakukan harus dilengkapi dengan ketidakpastian pengukuran yang menun-

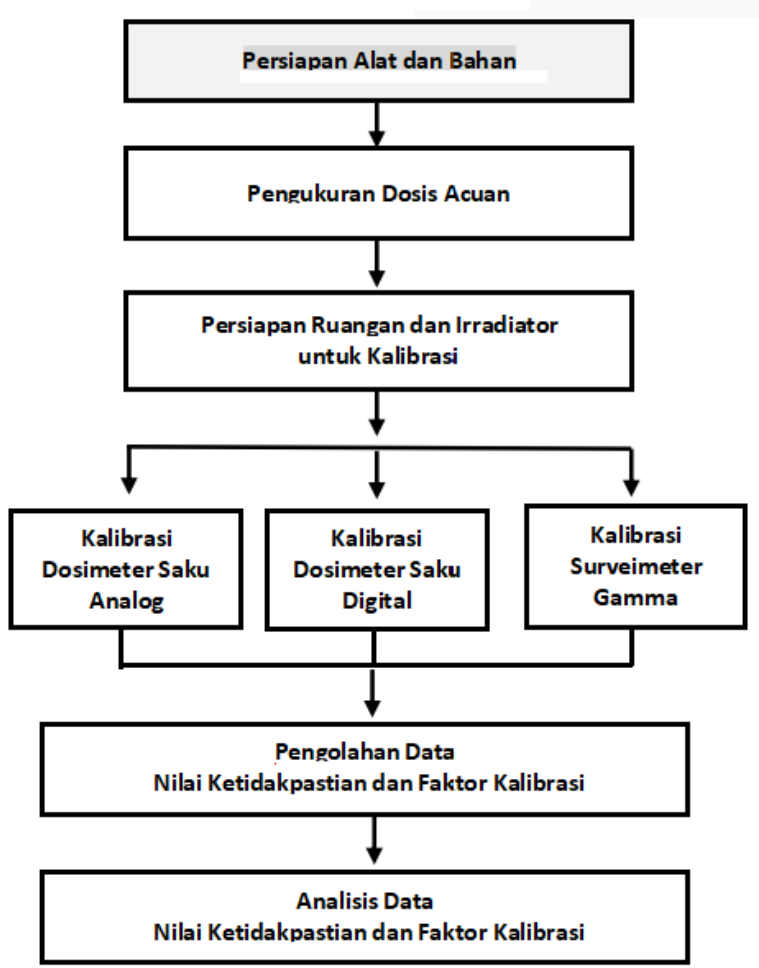

Gambar 1: Skema tata kerja penelitian jukan nilai simpangan dari suatu pengukuran yang telah dilakukan. Ketidakpastian menggambarkan kepercayaan saat pengambilan data kalibrasi alat. Semakin kecil ketidakpastian saat pengambilan data kalibrasi, semakin terpercaya data yang didapatkan. Di instalasi KAUR BPFK Surabaya, ketidakpastian ditentukan berdasarkan Instruksi Kerja Penentuan Ketidakpastian (IK-KAUR-04).

Selain deviasi standar dan simpangan baku rata-rata, beberapa faktor ketidakpastian yang berpengaruh pada faktor kalibrasi di antaranya adalah ketidakpastian dari laju dosis (Upr), ketidakpastian tipe A dari alat atau standard deviasi dari alat tersebut (UA), ketidakpastian resolusi (Ures), ketidakpastian tekanan udara $\left(\mathrm{U}_{P}\right)$, ketidakpastian jarak ke detektor (Ud),ketidakpastian temperatur $\left(\mathrm{U}_{T}\right)$, ketidakpastian waktu paruh $\left(\mathrm{UT}_{1 / 2}\right)$, dan ketidakpastian timer (Utimer) [5, 6]. Faktor ketidakpastian ini telah dibahas pada studi sebelumnya dengan nilai masing-masing ketidakpastian dapat dihitung sesuai acuan yang telah ditetapkan oleh BPFK Surabaya. Dari beberapa ketidakpastian tersebut dapat ditentukan ketidakpastian bentangan $\mathrm{U}$ yang dapat dirumuskan sebagai berikut

$$
U=k \cdot U_{c}
$$

dengan $\mathrm{k}$ adalah faktor cakupan dan $\mathrm{U}_{c}$ adalah ketidakpastian standar gabungan [5, 7]. Perhitungan ketidakpastian standar gabungan dapat dilihat pada studi sebelumnya [5, 7] dan faktor cakupan didapatkan dari kurva distribusi-t dua arah dari derajat kebebasan efektif yang dapat diturunkan dari faktorfaktor ketidakpastian yang telah dibahas sebelumnya.

Pada penelitian ini dilakukan kalibrasi pada 40 buah dosimeter personal berupa dosimeter saku analog dan digital serta 10 buah surveimeter. Sumber radiasi Cs-137 digunakan sebagai acuan dan faktor ketidakpastian seperti yang telah disebutkan di atas dihitung untuk mendapatkan faktor kalibrasi. Dari penelitian ini dapat ditentukan dosimeter personal dan surveimeter yang masih layak dipakai serta didapatkan metode yang relatif akurat untuk kalibrasi alat ukur radiasi di Instalasi KAUR BPFK Surabaya.

\section{TATA KERJA}

Kalibrasi alat ukur radiasi berupa dosimeter saku dan surveimeter gamma dilakukan di Instalasi KAUR BPFK Surabaya menggunakan metode substitusi sesuai pedoman Safety Report Series (SRS) no 16 tahun 2000 dari International Atomic Energy Agency (IAEA), Metode Kerja Kalibrasi Dosimeter Perorangan Gamma (MK-KAUR-03) serta Metode Kalibrasi Survey Meter Gamma (MK-KAUR-04). Alat ukur radiasi yang dikalibrasi merupakan alat ukur radiasi yang digunakan pada sejumlah rumah sakit dan pusat layanan kesehatan yang ada di Propinsi Jawa Timur. Pada penelitian ini digunakan 20 buah dosimeter saku analog, 20 buah dosimeter saku digital dan 10 buah surveimeter gamma. Langkah-langkah dalam penelitian ini meliputi pengukuran dosis acuan, persiapan ruang penyinaran irradiator, kalibrasi dosimeter saku analog, kalibrasi dosimeter saku digital dan kalibrasi surveimeter gamma. Skema tata kerja pada penelitian ini dapat dilihat pada Gambar 1. 
TABEL I: Hasil perhitungan nilai ketidakpastian bentangan pada salah satu dosimeter saku analog.

\begin{tabular}{|c|c|c|c|c|c|c|c|c|}
\hline $\begin{array}{l}\text { Ketidak- } \\
\text { pastian }\end{array}$ & Distr & Tipe & $\begin{array}{c}\mathrm{U} \\
(\%)\end{array}$ & K & $\begin{array}{c}\mathrm{U}_{i} \\
(\%)\end{array}$ & $\mathrm{c}_{i}$ & $\mathrm{U}_{i} \mathrm{c}_{i}$ & $\begin{array}{r}\left(\mathrm{U}_{i} \mathrm{c}_{i}\right)^{2} \\
(\%)\end{array}$ \\
\hline Upr & $\mathrm{N}$ & B & 2,90 & 2,00 & 1,450 & 1 & 1,450 & 2,103 \\
\hline UA & $\mathrm{N}$ & A & 0,00 & 1,00 & 0,000 & 1 & & 0,000 \\
\hline Ures & Rect & B & 2,08 & 73 & 1,204 & 1 & 204 & 1,450 \\
\hline $\mathrm{Up}$ & $\mathrm{N}$ & B & 0,01 & 2,00 & 0,004 & 1 & 0,004 & 0,000 \\
\hline Ud & $\mathrm{N}$ & B & 0,02 & 2,00 & 0,008 & 1 & 0,008 & 0,000 \\
\hline UT & $\mathrm{N}$ & B & 0,58 & 2,00 & 0,290 & 1 & 0,290 & 0,084 \\
\hline $\mathrm{UT} 1 / 2$ & $\mathrm{~N}$ & B & 0,27 & 2,00 & 0,13 & 1 & 0,133 & 0,018 \\
\hline Utimer & Rect & B & 0,41 & 1,73 & 0,24 & 1 & 0,237 & 0,056 \\
\hline \multicolumn{8}{|c|}{ Sums } & 3,71 \\
\hline \multicolumn{8}{|c|}{ Ketidakpastian standard gabungan (uc) $(\%)$} & 1,93 \\
\hline \multicolumn{8}{|c|}{ Derajat kebebasan efektif } & 120,08 \\
\hline \multicolumn{8}{|c|}{ Faktor cakupan, $\mathrm{k}$ untuk $\mathrm{v}_{\text {eff }}$ dan CL $95 \%$} & 1,98 \\
\hline \multicolumn{8}{|c|}{ Ketidakpastian bentangan, U = k.uc, $(\%)$} & 3,81 \\
\hline
\end{tabular}

\section{Pengukuran dosis acuan}

Sebelum memulai kalibrasi hal yang perlu diketahui adalah besarnya dosis acuan dari sumber Cs-137 yang digunakan. Pengukuran dosis acuan dilakukan dengan alat ukur standar yang telah terkalibrasi dan tertelusur secara Internasional dengan menggunakan Metode Kerja Pengukuran Output Cs-137 (MK-KAUR-01). Sebelum alat ukur standar digunakan terlebih dahulu dilakukan cek stabilitas untuk menjamin mutu kebenaran data yang diperoleh dengan menggunakan sumber Sr-90 sesuai Metode Kerja Pengecekan Antara Alat Ukur Standar Dosimeter (MK-KAUR-07). Alat ukur standar ini dikatakan stabil jika memiliki standard deviasi $<1 \%$ dari data cek stabilitas sebelumnya melalui perhitungan peluruhan Sr90. Pengukuran sumber acuan dilakukan pada berbagai jarak dan variasi ketebalan absorber. Pengukuran langsung yang dilakukan berupa besaran kerma udara $(\mathrm{Ku})$ dalam satuan Gray (Gy) sesuai Metode Kerja Pengukuran Output Cs-137 (MKKAUR-01). Untuk keperluan kalibrasi, besaran kerma udara akan dikonversi kedalam besaran turunan sesuai kebutuhan dengan menggunkan Metode Kerja Perhitungan Dosis Acuan (MK-KAUR-02).

\section{Persiapan ruang penyinaran dan irradiator}

Persiapan alat ukur dan peralatan penunjang seperti termometer, higrometer, laser, CCTV dan satu meja kalibrasi dilakukan sebelum kalibrasi ruang. Semua hal-hal tersebut harus dipastikan dalam keadaan baik dan siap digunakan. Selain itu irradiator dari ruang pengamatan juga harus disiapkan dan proses ini memakan waktu kurang lebih 15 menit.

\section{Kalibrasi dosimeter saku analog}

Pada kalibrasi dosimeter analog, dosimeter diletakkan pada meja kalibrasi dengan jarak $200 \mathrm{~cm}$ dari sumber Cs-137. Sebelum diletakkan di meja kalibrasi, dosimeter analog dihubungkandengan sumber daya dan diset ulang sehingga menunjukkan skala pembacaan pada angka nol. Laser digunakan
TABEL II: Hasil pengukuran pada salah satu dosimeter saku digital.

\begin{tabular}{|c|c|c|c|}
\hline No & $\begin{array}{c}\text { Dosis Acuan } \\
(\mu \mathrm{Sv} / \mathrm{h})\end{array}$ & $\begin{array}{c}\text { Dosis Terbaca } \\
(\mu \mathrm{Sv} / \mathrm{h})\end{array}$ & $\begin{array}{c}\text { Dosis Terukur } \\
(\mu \mathrm{Sv} / \mathrm{h})\end{array}$ \\
\hline 1 & \multirow{5}{*}{97,376} & 96,77 & 96,487 \\
\hline 2 & & 96,89 & 96,607 \\
\hline 3 & & 96,78 & 96,497 \\
\hline 4 & & 96,93 & 96,647 \\
\hline 5 & & 96,84 & 96,557 \\
\hline & Rata-rata dosis terukur & & 96,559 \\
\hline & Standard deviasi & & 0,06907 \\
\hline & Nilai faktor kalibrasi & & 1,01 \\
\hline
\end{tabular}

untuk mengetahui posisi yang tepat pada detektor sehingga posisi dosimeter analog berada tegak lurus terhadap titik tengah sumber radiasi. Setelah itu dilakukan penyinaran terhadap dosimeter analog dengan laju dosis $888,426 \mathrm{mR} / \mathrm{jam}$ selama waktu yang telah ditentukan dan hasil pengukuran yang didapat kemudian dicatat. Pengukuran dilakukan sebanyak 5 kali dan kondisi suhu serta kelembaban udara dicatat pada setiap pengukuran dosimeter.

\section{Kalibrasi dosimeter saku digital}

Dosimeter saku digital diletakkan pada meja kalibrasi dengan jarak yang telah ditentukan dari sumber Cs-137. Seperti pada dosimeter analog, posisi dosimeter saku digital dipastikan dengan laser dan dilakukan penyinaran pada dosimeter saku digital dengan laju dosis acuan yang telah ditentukan. Pengukuran juga dilakukan sebanyak 5 kali sesuai Metode Kerja Kalibrasi Dosimeter Perorangan Gamma (MK-KAUR-03) dengan pencatatan laju dosis, suhu serta kelembaban udara pada setiap pengukuran dosimeter saku digital.

\section{Kalibrasi surveimeter gamma}

Kalibrasi surveimeter gamma memiliki rentang ukur yang berbeda-beda sehingga masing-masing pengukuran harus dikalibrasi sesuai dengan rentangnya. Pemilihan rentang ukur dilakukan agar bacaan pada surveimeter tersebut tidak melebihi dari skala yang ada (overload). Surveimeter gamma yang akan dikalibrasi diletakkan pada meja kalibrasi dengan jarak yang telah ditentukan dari sumber radiasi Cs-137. Posisi dari surveimeter dipastikan dengan laser dan pengukuran dilakukan untuk semua rentang yang dimiliki oleh surveimeter gamma. Kalibrasi surveimeter gamma menggunakan tiga parameter yang berbeda yaitu pada skala satuan, puluhan dan ratusan sesuai Metode Kerja Kalibrasi Survey Meter Gamma (MK-KAUR-04).

\section{Perhitungan ketidakpastian gabungan dan faktor kalibrasi}

Dari data yang telah diperoleh baik untuk dosimeter analog, dosimeter digital dan surveimeter gamma dilakukan perhitungan nilai ketidakpastian gabungan dan faktor kalibrasi pada masing-masing alat ukur. Nilai ketidakpastian gabungan 
TABEL III: Nilai ketidakpastian bentangan dan faktor kalibrasi pada dosimeter saku analog dan digital.

\begin{tabular}{ccccc}
\hline \hline \multirow{2}{*}{ Nomor AUR } & \multicolumn{2}{c}{ Dosimeter Saku Analog } & \multicolumn{2}{c}{ Dosimeter Saku Digital } \\
& $\begin{array}{c}\text { Ketidakpastian Bentangan } \\
(\%)\end{array}$ & $\begin{array}{c}\text { Faktor } \\
\text { Kalibrasi }\end{array}$ & $\begin{array}{r}\text { Ketidakpastian Bentangan } \\
(\%)\end{array}$ & $\begin{array}{c}\text { Faktor } \\
\text { Kalibrasi }\end{array}$ \\
\hline 1 & 3,81 & 1,04 & 2,94 & 1,01 \\
2 & 3,81 & 1,04 & 2,94 & 0,98 \\
3 & 3,81 & 1,04 & 2,94 & 0,99 \\
4 & 3,21 & 1,11 & 2,64 & 1,00 \\
5 & 4,67 & 1,25 & 2,95 & 0,99 \\
6 & 3,81 & 1,04 & 2,66 & 0,99 \\
7 & 4,33 & 1,02 & 2,67 & 0,99 \\
8 & 4,16 & 1,03 & 2,67 & 0,98 \\
9 & 6,44 & 1 & 2,94 & 1,02 \\
10 & 7,25 & 1,04 & 2,95 & 1,02 \\
11 & 4,17 & 1,11 & 2,95 & 0,96 \\
12 & 6,55 & 1 & 2,95 & 1,00 \\
13 & 6,55 & 1 & 2,95 & 1,00 \\
14 & 8,65 & 1,04 & 2,95 & 1,00 \\
15 & 6,43 & 1 & 2,94 & 1,00 \\
16 & 6,43 & 1 & 2,68 & 0,98 \\
17 & 3,93 & 1 & 2,68 & 0,99 \\
18 & 4,05 & 1,05 & 2,67 & 1,00 \\
19 & 4,80 & 1,03 & 2,73 & 0,99 \\
20 & 4,18 & 1,11 & 2,65 & 0,99 \\
\hline Rata-rata & 5,05 & 1,04 & 2,82 & 0,99 \\
Standard Deviasi & 1,50 & 0,06 & 0,14 & 0,01 \\
\hline \hline
\end{tabular}

TABEL IV: Hasil pengukuran pada survei meter gamma untuk skala satuan, puluhan maupun ratusan.

\begin{tabular}{|c|c|c|c|c|c|c|c|c|c|}
\hline \multirow[b]{2}{*}{ No } & \multicolumn{3}{|c|}{ Skala satuan (mR/h) } & \multicolumn{3}{|c|}{ Skala puluhan $(\mathrm{mR} / \mathrm{h})$} & \multicolumn{3}{|c|}{ Skala ratusan $(\mathrm{mR} / \mathrm{h})$} \\
\hline & $\begin{array}{l}\text { Dosis } \\
\text { acuan }\end{array}$ & $\begin{array}{l}\text { Dosis } \\
\text { terbaca }\end{array}$ & $\begin{array}{l}\text { Dosis } \\
\text { terukur }\end{array}$ & $\begin{array}{l}\text { Dosis } \\
\text { acuan }\end{array}$ & $\begin{array}{c}\text { Dosis } \\
\text { terbaca }\end{array}$ & $\begin{array}{l}\text { Dosis } \\
\text { terukur }\end{array}$ & $\begin{array}{l}\text { Dosis } \\
\text { acuan }\end{array}$ & $\begin{array}{l}\text { Dosis } \\
\text { terbaca }\end{array}$ & $\begin{array}{c}\text { Dosis } \\
\text { terukur }\end{array}$ \\
\hline 1 & & 7 & 7 & & 55 & 55 & & 750 & 750 \\
\hline 2 & & 7 & 7 & & 55 & 55 & & 750 & 750 \\
\hline 3 & 7,326 & 7 & 7 & 55,545 & 60 & 60 & 708,056 & 750 & 750 \\
\hline 4 & & 7 & 7 & & 60 & 60 & & 750 & 750 \\
\hline 5 & & 7 & 7 & & 55 & 55 & & 750 & 750 \\
\hline Rata-rata & & & 7 & & & 57,00 & & & 750 \\
\hline Standard & & & & & & & & & \\
\hline Deviasi & & & 0,00 & & & 2,73861 & & & 0,00 \\
\hline Nilai Faktor & & & & & & & & & \\
\hline Kalibrasi & & & 1,05 & & & 0,97 & & & 0,94 \\
\hline
\end{tabular}

dan faktor kalibrasi dapat dihitung menggunakan Pers.(1) dan (2) sesuai Instruksi Kerja Penentuan Ketidakpastian (IK-KAUR-04). Untuk menghitung nilai-nilai tersebut, dibutuhkan beberapa data acuan yang telah diukur dan diterbitkan oleh BPFK Surabaya antara lain laju kerma udara (KU); laju dosistara ambient $\left(\mathrm{H}^{*} 10\right)$; laju dosistara perorangan $(\mathrm{Hp}(10))$; serta laju paparan $(\mathrm{X})$ pada jarak penyinaran 175 $\mathrm{cm}, 200 \mathrm{~cm}, 225 \mathrm{~cm}, 250 \mathrm{~cm}$, dan $270 \mathrm{~cm}$ baik tanpa absorber maupun menggunakan absorber (dengan absorber 1/10, 1/100 dan 1/1000).

\section{HASIL DAN DISKUSI}

\section{Hasil kalibrasi dosimeter saku analog dan digital}

Pada kalibrasi dosimeter saku analog dosis acuan yang digunakan adalah $50 \mathrm{mR}$ dengan laju dosis $888,426 \mathrm{mR} / \mathrm{jam}$ sehingga diperlukan waktu penyinaran $\pm 3,38$ menit. Pada pengukuran ini diketahui radiasi latar (background radiation) adalah 0. Pengulangan pengambilan data dilakukan sebanyak 5 kali. Pengukuran dilakukan pada tekanan udara 1011,9 hPa, suhu udara $20,7^{\circ} \mathrm{C}$ dan kelembaban udara $69,4 \%$. Dosimeter saku analog yang digunakan memiliki resolusi $2 \mathrm{mR}$. Hasil perhitungan ketidakpastian bentangan seperti yang dijelaskan pada Pers.(2) pada salah satu dosimeter saku analog digam- 
TABEL V: Nilai ketidakpastian bentangan dan faktor kalibrasi pada surveimeter gamma.

\begin{tabular}{|c|c|c|c|c|c|c|}
\hline \multirow{2}{*}{$\begin{array}{l}\text { Surveimeter } \\
\text { Gamma }\end{array}$} & \multicolumn{3}{|c|}{ Ketidakpastian bentangan (\%) } & \multicolumn{3}{|c|}{ Faktor kalibrasi } \\
\hline & satuan & puluhan & ratusan & satuan & puluhan & ratusan \\
\hline 1 & 3,35 & 6,23 & 3,26 & 1,05 & 6,23 & 3,26 \\
\hline 2 & 3,35 & 3,76 & 3,09 & 1,01 & 3,76 & 3,09 \\
\hline 3 & 3,21 & 3,37 & 3,22 & 1,02 & 3,37 & 3,22 \\
\hline 4 & 3,41 & 3,38 & 3,22 & 1,03 & 3,38 & 3,22 \\
\hline 5 & 3,19 & 2,99 & 2,76 & 0,93 & 2,99 & 2,76 \\
\hline 6 & 3,24 & 3,29 & 2,80 & 1,04 & 3,29 & 2,80 \\
\hline 7 & 3,23 & 3,03 & 2,82 & 1,01 & 3,03 & 2,82 \\
\hline 8 & 3,24 & 3,03 & 2,83 & 1,04 & 3,03 & 2,83 \\
\hline 9 & 3,24 & 3,02 & 2,81 & 1,04 & 3,02 & 2,81 \\
\hline 10 & 4,15 & 4,68 & 2,81 & 1,04 & 4,68 & 2,81 \\
\hline Rata-rata & 3,36 & 3,68 & 72,96 & 1,02 & 3,68 & 2,96 \\
\hline \multicolumn{7}{|l|}{ Standard } \\
\hline Deviasi & 0,29 & 1,03 & 0,21 & 0,03 & 1,03 & 0,21 \\
\hline
\end{tabular}

barkan pada Tabel I.

Pada kalibrasi dosimeter saku digital, laju dosis acuan yang digunakan adalah $97,376 \mu \mathrm{Sv} / \mathrm{h}$. Radiasi latar yang terukur saat kalibrasi adalah $0,283 \mu \mathrm{Sv} / \mathrm{h}$. Tekanan udara pada saat pengukuran tercatat $1008,7 \mathrm{hPa}$, suhu udara $21^{\circ} \mathrm{C}$, kelembaban udara $56,9 \%$ dan alat dosimeter digital memiliki resolusi $0,001 \mu \mathrm{Sv} / \mathrm{h}$. Hasil pengukuran dosis pada salah satu dosimeter saku digital diberikan di Tabel II. Untuk menentukan nilai ketidakpastian gabungan pada dosimeter saku analog, ketidakpastian peluruhan laju paparan diukur tanpa absorber pada jarak $200 \mathrm{~cm}$ dan didapatkan nilai ketidakpastian laju paparan sebesar $\pm 2,90 \%$. Sedangkan pada dosimeter saku digital, digunakan absorber 1/100 dan ketidakpastian laju paparan pada jarak $200 \mathrm{~cm}$ terukur adalah $\pm 2,90 \%$.

Nilai faktor kalibrasi pada dosimeter saku analog dan digital dihitung menggunakan Pers.(1) dengan memperhatikan laju dosis serta nilai ketidakpastian. Nilai ketidakpastian bentangan gabungan dan faktor kalibrasi pada 20 dosimeter saku analog dan 20 dosimeter saku digital ditunjukkan pada Tabel III. Dari ke-20 dosimeter saku analog yang dikalibrasi, terdapat satu dosimeter yang mempunyai faktor kalibrasi di luar ambang yang disyaratkan yaitu dosimeter ke-5 dengan FK 1,25 .

Dosis yang terbaca pada dosimeter tersebut juga mempunyai simpangan $20 \%$ dari dosis acuan sehingga dosimeter ini direkomendasikan untuk tidak digunakan lagi dalam praktek sehari-hari. Hal ini dipengaruhi oleh kualitas detektor pada dosimeter yang menurun karena pengaruh umur dosimeter. Pada dosimeter yang lain ditemukan simpangan pembacaan dosis sebesar $10 \%$ namun nilai FK masih dalam ambang batas yang disyaratkan, sehingga AUR ini masih dapat digunakan untuk praktek sehari-hari.

Pada kalibrasi 20 dosimeter digital diketahui semua dosimeter mempunyai FK dalam ambang batas yang dapat diterima dan nilai FK yang terukur relatif lebih baik dibandingkan dengan FK dosimeter analog. Sehingga semua dosimeter digital direkomendasikan dapat digunakan untuk pengukuran radiasi. Hal ini dipengaruhi oleh resolusi dosime- ter digital yang lebih akurat dan teliti sehingga memperkecil nilai ketidakpastian dan meningkatkan nilai FK.

\section{Hasil kalibrasi surveimeter gamma}

Pada kalibrasi 10 surveimeter gamma digunakan 3 skala yaitu satuan, puluhan dan ratusan, absorber yang digunakan pada masing-masing skala adalah 1/100 untuk skala satuan, 1/10 untuk skala puluhan dan tanpa absorber untuk skala ratusan. Ketidakpastian laju paparan dari ketiga absorber pada surveimeter gamma diambil pada jarak $225 \mathrm{~cm}$ dan diketahui sebesar $\pm 2,60 \%$. Kalibrasi survei meter gamma dilakukan pada tekanan udara $1007,4 \mathrm{hPa}$, suhu udara $21,3^{\circ} \mathrm{C}$ dan kelembaban udara $60,7 \%$. Resolusi pada surveimeter gamma untuk masing-masing skala adalah $0,25 \mathrm{mR} / \mathrm{h}$ untuk skala satuan, 2,5 mR/h untuk skala puluhan dan $25 \mathrm{mR} / \mathrm{h}$ untuk skala ratusan. Laju dosis paparan yang digunakan serta dosis terbaca dan terukur pada skala satuan, puluhan maupun ratusan digambarkan pada Tabel IV.

Nilai ketidakpastian bentangan gabungan dan faktor kalibrasi pada surveimeter gamma, baik pada skala satuan, puluhan dan ratusan ditunjukkan pada Tabel V. Dari tabel tersebut diketahui bahwa nilai FK dari 10 surveimeter gamma yang digunakan menunjukan hasil kalibrasi yang baik untuk skala satuan, puluhan maupun ratusan, sehingga surveimeter gamma tersebut masih layak digunakan.

\section{SIMPULAN}

Dari penelitian yang telah dilakukan 40 dosimeter saku yang diuji, 39 dosimeter dikatakan baik karena memenuhi standar kalibrasi dan 1 dosimeter saku analog tidak layak digunakan karena mempunyai nilai faktor kalibrasi di luar standard yang telah ditetapkan. Dari 10 surveimeter gamma yang diuji semuanya memenuhi standard sehingga semua surveimeter masih layak dipakai. 
[1] Z. Alatas,"Buku Pintar Nuklir", BATAN, Jakarta, 2009.

[2] Peraturan Kepala BAPETEN No.1 tahun 2006 tentang "Laboratorium Dosimetri, Kalibrasi Alat Ukur Radiasi Dan Keluaran Sumber Radiasi Terapi, dan Standardisasi Radionuklida", BAPETEN, Jakarta, 2006.

[3] Peraturan Menteri Kesehatan No. 54 tahun 2015 tentang "Pengujian dan Kalibrasi Alat Kesehatan”, Kementerian Kesehatan Republik Indonesia, Jakarta, 2015.

[4] JCGM 200:2008, "International vocabulary of metrology - Basic and general concepts and associated terms", Joint Committee for Guides in Metrology, 2008.

[5] V. Lewis, M.J. Woods, P. Burges, S. Green, J. Simpson and J.
Wardle, "Measurement Good Practice Guide No. 49, The Assessment of Uncertainty in Radiological Calibration and Testing, National Physical Laboratory, UK, 2005.

[6] Nazaroh, Pedoman Pengukuran Laju Kerma Udara dan Kalibrasi Alat Ukur Radiasi Tingkat Proteksi serta Penilaian Ketidakpastiannya Berdasarkan The Measurement Good Practice Guide No. 49/2003, Jurnal Standardisasi, vol. 12, no. 2, hlm. 118-127, 2010.

[7] Nazaroh, Kalibrasi Dosimeter Saku Gamma (DSG) dan TLD/Film Badge (FB) di Laboratorium PTKMR BATAN, Jurnal Standardisasi, vol. 13, no. 2, hlm. 120-128 (2011). 